\title{
O PATRIMÓNIO CULTURAL NO ENSINO DE HISTÓRIA: ENTRE TEORIA E PRÁTICA
}

\author{
Maria Helena Pinto ${ }^{1}$
}

\begin{abstract}
Resumo: O ensino de história, se transmitir um conhecimento histórico factual e acabado, baseado numa narrativa única e numa identidade nacional exclusiva, pode produzir inúmeros obstáculos à construção da compreensão e consciência históricas dos alunos. A investigação em Ensino de História, em Educação Histórica e em Educação Patrimonial, realizada nas últimas décadas com professores e estudantes, tem procurado promover o ensino e a aprendizagem de conteúdos substantivos e conceitos disciplinares, o questionamento e discussão sobre diferentes fontes e o desenvolvimento do pensamento analítico e crítico. Estes objetivos apoiaram estudos de investigação, de natureza qualitativa, sobre a utilização do património cultural em aulas de história, e como este auxilia ou restringe o desenvolvimento de uma consciência patrimonial e a compreensão das interpretações históricas. De entre as conclusões principais da investigação relatada, destacam-se as vantagens da exploração do meio local, a partir de problemas próximos interesses dos alunos, analisando diversas fontes, materiais e imateriais, questionando, levantando hipóteses e construindo interpretações baseadas em evidências.
\end{abstract}

Palavras-chave: Educação Patrimonial, Educação Histórica, Pensamento Crítico, Consciência Patrimonial.

\section{CULTURAL HERITAGE IN HISTORY TEACHING: BETWEEN THEORY AND PRACTICE}

\begin{abstract}
The teaching of history, if it conveys a factual and finished historical knowledge, based on a single narrative and on an exclusive national identity, may produce countless obstacles to the construction of students' historical understanding and consciousness. Research in History Teaching, History Education and Heritage Education, carried out in recent decades with teachers and students, has sought to promote the teaching and learning of substantive content and disciplinary concepts, the questioning and discussion of different sources and the development of analytical and critical thinking. These objectives have supported research studies, of a qualitative nature, on the use of cultural heritage in history classes, and how this assists or restricts the development of a heritage consciousness and the understanding of historical interpretations. Among the main conclusions of the reported research, were highlighted the advantages of exploring the local environment, from problems close to students' interests, analysing various material and immaterial sources, questioning, raising hypotheses and building evidence-based interpretations.
\end{abstract}

Keywords: Heritage Education, History Education, Critical Thinking, Heritage Consciousness.

\footnotetext{
${ }^{1}$ Doutora em Ciências da Educação (História e Ciências Sociais) pela Universidade do Minho, Portugal. Professora da Universidade do Porto - Faculdade de Letras - CITCEM - Centro de Investigação Transdisciplinar «Cultura, Espaço e Memória»: Porto, Portugal. E-mail: mhelenapinto@gmail.com.
} 


\section{EL PATRIMONIO CULTURAL EN LA ENSEÑANZA DE LA HISTORIA: ENTRE LA TEORÍA Y LA PRÁCTICA}

Resumen: La enseñanza de la historia, si transmite un conocimiento histórico objetivo y acabado, basado en una narrativa única y una identidad nacional exclusiva, puede producir numerosos obstáculos a la construcción de la comprensión y la conciencia históricas de los estudiantes. La investigación en Enseñanza de la Historia, Educación Histórica y Educación del Patrimonio, realizada en las últimas décadas con profesores y alumnos, ha buscado promover la enseñanza y el aprendizaje de contenidos sustantivos y conceptos disciplinarios, el cuestionamiento y la discusión de diferentes fuentes y el desarrollo del pensamiento analítico y crítico. Estos objetivos han apoyado la realización de estudios de investigación, de carácter cualitativo, sobre la utilización del patrimonio cultural en las clases de historia y sobre la manera en que ello contribuye o restringe el desarrollo de la conciencia patrimonial y la comprensión de las interpretaciones históricas. Entre las principales conclusiones de la investigación reportada, destacamos las ventajas de explorar el entorno local, desde problemas cercanos a los intereses de los estudiantes, analizando diversas fuentes, materiales e inmateriales, cuestionando, planteando hipótesis y construyendo interpretaciones basadas en la evidencia.

Palabras clave: Educación Patrimonial, Educación Histórica, Pensamiento Crítico, Conciencia patrimonial.

\section{Introdução}

No presente texto apresenta-se uma reflexão sobre abordagens de educação histórica e educação patrimonial com base em actividades educativas relacionadas com o uso do património cultural no ensino de história.

Procura-se contribuir para a investigação sobre consciência histórica, na perspectiva patrimonial, em boa parte inspirada nas obras de Rüsen (2001, 2004) e Lee (2002, 2003), nomeadamente no âmbito da Educação Histórica e Social, com enfoque no ensino e aprendizagem de história.

Concretiza-se, esta reflexão, apresentando um estudo empírico por meio do qual se procurou conhecer as concepções e de que forma um grupo de professores de história do norte de Portugal, em formação contínua, revelam usar as fontes patrimoniais em atividades de ensino de história e que tipos de consciência revelam em termos de relação identitária com o património. A metodologia caracteriza-se por uma abordagem descritiva, de natureza essencialmente qualitativa. A este respeito, considera-se a investigação-ação como o enfoque adequado para propiciar aprendizagens significativas, onde a exploração do meio local, partindo de problemas próximos dos interesses dos alunos, analisando diversas fontes 
materiais e outras, e chegando a conclusões sobre os problemas colocados inicialmente (PINTO, 2016), constitui o eixo fundamental das atividades de ensino e aprendizagem através do património cultural.

O estudo salienta o interesse da utilização de fontes patrimoniais no ensino de história, defendendo que os professores podem desempenhar um papel fundamental para que os alunos dêem sentido ao património como evidência histórica, e não apenas como simples ilustração. É essencial, para isso, que os professores tomem consciência da importância do uso da evidência de acordo com critérios metodológicos.

\section{O uso do património cultural em educação}

O Património é geralmente apresentado como construção material e simbólica do passado. Porém, a maior parte dos estudos desenvolvidos nas últimas décadas insistem no facto de aquilo a que chamamos 'património' ser uma construção da sociedade presente, de forma a promover sentidos de identidades. Segundo Lowenthal (1999), quer a memória quer a história derivam de vestígios físicos e ganham ênfase a partir deles. Os vestígios tangíveis garantem uma proximidade autêntica que nos leva a assumir que ali existiu efectivamente um passado. Mas, na verdade, os vestígios físicos têm limitações como informação: eles não falam e, por isso, requerem interpretação.

Hooper-Greenhill (1999), referindo-se à interpretação dos objectos de museus, sugere que a construção de significados depende do conhecimento anterior e dos valores préexistentes: "Vemos de acordo com o que sabemos e damos sentido de acordo com o que vemos" (p. 13). Desta forma, construímos os nossos significados, mas não de forma definitiva. A construção de significados depende da forma como relacionamos o passado com o presente. Toda a interpretação é, por isso, historicamente situada: "as pessoas constroem activamente as interpretações da sua própria experiência, e o significado construído surge de um prévio conhecimento e da experiência individual, mas também das comunidades interpretativas em que o indivíduo está filiado" (p. 23). Assim, a construção de significados é individual e social.

Sendo a aprendizagem entendida como "um processo de construção interpretativo e recursivo por parte dos alunos em interacção com o mundo físico e social" (FOSNOT, 1999, p. 53), se as situações apresentadas forem significativas para os alunos, estes aprendem algo de novo. Os novos conceitos são integrados nas ideias prévias se com elas tiverem alguma 
relação. Quando estas ideias são demasiado discrepantes da sua experiência, os alunos poderão converter essas ideias em outras, não científicas, mas que lhes sejam mais familiares. Por isso, o senso comum das crianças e adolescentes, as suas experiências, os seus pontos de vista, devem ser acolhidos pelos educadores não como obstáculos à aprendizagem, mas como âncoras para construções mais elaboradas.

O pensamento histórico dos estudantes pode ser estimulado quando estes se envolvem em actividades com evidências da vida de comunidades humanas no passado (NAKOU, 2001). Enquanto no ambiente escolar os jovens tendem a reproduzir a informação, no museu parecem 'ver' os objetos em termos históricos. Nakou (2003) salienta que os objectos dos museus levam os alunos a tentarem descodificar o seu significado, permitindo ainda reconhecer que o passado não pode ser conhecido directamente. Esta situação é muito interessante para a educação, pois os jovens parecem evocar as suas experiências e ideias prévias, mas procuram ir além delas. Guiados por questões apropriadas, podem desenvolver mais facilmente o seu pensamento histórico.

Ramos (2004) lembra que, no quotidiano, usamos uma infinidade de objetos, mas raramente pensamos sobre eles, o que limita também a reflexão sobre os objectos dos museus. Por isso, defende a realização de actividades vinculadas à "historicidade dos objectos" na própria sala de aula, para que o professor motive a percepção dos alunos a partir de materiais do quotidiano, pois através de perguntas sobre objectos, abre-se espaço para uma percepção mais ampla diante da exposição museológica; alarga-se a postura crítica sobre o mundo envolvente.

Aprender a reflectir a partir da cultura material, através de uma "alfabetização visual", sobre as relações entre sujeito e objecto é um exercício que deve partir do próprio quotidiano, pois assim se estabelece o diálogo, o conhecimento do novo na experiência vivida. Deste modo, os objectos, expostos no museu ou na cidade, podem tornar-se fontes de educação patrimonial e, nesse sentido, a aprendizagem de história não deve ser realizada somente na sala de aula, pois como sugere Ramos (2004, p. 48) a "pedagogia do objecto" pode usar-se em muitos outros territórios.

Proporcionar aos jovens o contacto directo com diferentes tipologias de património, fomentar a sua leitura a níveis cada vez mais exigentes, são práticas educativas com enormes potencialidades. Por isso, Levstik, Henderson e Schlarb (2005) em seus estudos com fontes arqueológicas, referem que os estudantes (de escolas do ensino fundamental, nos Estados Unidos) parecem reconhecer os meios pelos quais a cultura molda e é moldada pela interação 
humana, mediante a ligação de objectos pessoais ou familiares dos alunos às reconstruções arqueológicas do passado. Em geral, os alunos parecem compreender que os vestígios materiais do passado ajudam a responder às questões arqueológicas, e que esses vestígios são incompletos. Esta visão da arqueologia como uma pesquisa de final aberto, incompleta, representa um forte contraste com as suas descrições da História, que consideram ser uma narrativa pronta. E, se os alunos nem sempre estabelecem ligações claras entre os vestígios materiais e as culturas que os produziram, reconhecem que a observação cuidada dos artefactos conduz a melhores inferências e a uma história mais completa.

A utilização fontes patrimoniais em abordagens de história local, ou de âmbito mais lato, pode levar os alunos a reflectirem sobre evidência histórica, a questionarem, a ouvirem diferentes argumentos, a justificarem decisões. Como salientam Ashby, Lee e Shemilt (2005), os alunos chegam à sala de aula com ideias prévias, mas a relação entre essas ideias prévias a analisar e os conhecimentos de conceitos-chave a ensinar é essencial para assegurar que se verifica a progressão dos conhecimentos dos alunos. Os professores podem desenvolver nos alunos a consciência acerca dos seus conhecimentos e permitir-lhes ver que algumas questões resolvem problemas enquanto outras respostas não o fazem. Este tipo de consciência também ajuda os alunos a reconhecer que as respostas de outros colegas podem ser relevantes para a resolução dos seus problemas.

A realização de actividades educativas de exploração de fontes patrimoniais pode contribuir para a progressão do pensamento histórico dos jovens, pois implica o reconhecimento da evidência como meio para compreender conceitos históricos e sociais (ASHBY, 2003; COOPER, 1992, 2004) e envolve, acima de tudo, aprendizagens significativas e em contexto (PINTO, 2011; SCHMIDT e GARCIA, 2007).

No entanto, se é consensual a importância da utilização dos museus e do património como espaços e recursos educativos para grupos de diferentes idades, e os resultados dos estudos apresentados em diversos encontros académicos ou profissionais têm vindo a mostrar a importância da educação patrimonial nas experiências de aprendizagem dos alunos, poucas escolas a incluem no seu projecto educativo, e muitos professores não tiveram a possibilidade de contactar com metodologias específicas neste domínio.

Em Portugal, os documentos curriculares fazem breves referências ao património e incluem o estudo direto e o contacto com o património histórico-cultural nacional e regional/local, mas não atribuem a temática do património a uma área curricular específica e autónoma (PINTO, 2016). Além disso, as referências ao património são, em geral, 
superficiais. Dada a transversalidade que caracteriza a educação patrimonial, e que resulta da heterogeneidade inerente ao património, em sua diversidade tipológica, parece de toda a pertinência a abordagem de fontes patrimoniais em ciências sociais (ESTEPA e CUENCA, 2006). Se é verdade que os extensos programas não disponibilizam muito tempo para o detalhe, para a perspetiva local, para a discussão e a argumentação refletida, também é possível, através da seleção de assuntos que poderão ser tratados no âmbito da história local, introduzir de forma interessante e adequada ao currículo, a abordagem do património cultural (PINTO e MOLINA, 2015) em educação histórica.

Será, também, de toda a pertinência que os professores tenham preparação no ensino a partir de objectos e sítios históricos, uma vez que se sentem geralmente mais aptos a usarem textos do que fontes materiais, sendo bastante comum o seu uso para ilustrar a informação. É importante que os professores se sintam preparados para lidar com objetos, analisando-os de forma a esclarecer a sua produção, função, etc., integrando-os em contexto.

Ashby (2006) salienta que, após três décadas de trabalho crítico com fontes, as pesquisas no Reino Unido sugerem que muitos alunos possuem uma forte propensão para tratar a informação tal como ela é dada, e fazer apelo às autoridades, embora reconheçam que o nosso conhecimento do passado resulta de materiais que foram deixados para trás. Para progredirem no seu conhecimento histórico, os alunos precisam de "compreender que fonte não é o mesmo que evidência", e desenvolver uma "compreensão conceptual da relação entre fontes e afirmações" (p. 156). É a natureza das questões sobre o passado que determina o que conta como evidência na validação das afirmações, mas diferentes questões estão relacionadas de diferentes formas com a evidência, pelo que essa relação também determina os diferentes estatutos das afirmações feitas.

Várias pesquisas têm afirmado a possibilidade de desenvolvimento do pensamento histórico das crianças e dos jovens, nomeadamente pela aprendizagem de conceitos como a noção de temporalidade histórica, por meio da acção mediadora dos objectos da cultura material e do professor. Tal propósito, envolve não só a compreensão de situações do passado apresentadas por especialistas, mas também que os alunos experimentem procedimentos metodológicos que permitam interpretar diferentes fontes em termos de evidência histórica (ASHBY, 2003; SHEMILT, 1987), por exemplo, através da realização de actividades relacionadas com o património histórico-cultural de uma comunidade. Salienta-se, por isso, a importância da proposta de tarefas que incluam o uso de fontes patrimoniais, desde objetos em contexto ou em museus, a edifícios integrados em sítios históricos (SANTACANA e 
LLONCH, 2012; SANTACANA e MARTINEZ, 2013) e que desafiem as preconceções dos alunos (ASHBY, LEE e SHEMILT, 2005), fomentando a interpretação de vestígios existentes no meio local e a discussão sobre as ações humanas no passado e sua relação com o presente.

Pelo exposto, considera-se fundamental, no âmbito da educação, a realização de estudos sistemáticos e segundo critérios metodológicos, sobre experiências educativas relacionadas com o uso de fontes patrimoniais e sua interpretação contextualizada. Por outro lado, não devemos esquecer a sensibilização para o património -do contexto local ao internacional- e o seu papel na construção de identidades, pois tudo isto pressupõe a construção de pensamento crítico e consciência histórica.

\section{Consciência patrimonial e histórica}

Segundo Lowenthal (1999), conhecemos o nosso passado porque lembramos coisas, lemos ou ouvimos histórias e vivemos entre vestígios de tempos anteriores. O passado rodeianos - "toda a consciência do presente se baseia nas percepções e actos do passado" (p. 185) e cada ação retém conteúdo residual de outros tempos. Por isso, salienta a necessidade de discutir os elementos que têm vindo a moldar a consciência e a identidade coletiva e individual, uma vez que afetam a forma como os alunos aprendem história e os seus pontos de vista sobre o património e sobre o passado em geral (LOWENTHAL, 1999).

Isabel Barca (2007) define a consciência histórica como uma atitude de orientação de cada pessoa no seu tempo, sustentada reflectidamente pelo conhecimento da História. Distingue-se, por isso, de uma simples resposta de senso comum às exigências práticas dessa mesma orientação temporal, baseada exclusivamente em sentimentos de pertença - de identidade local, nacional, profissional ou outra.

Segundo Rüsen (2001), a consciência histórica é estimulada e influenciada pelas experiências do presente, pelo que a sua função de atribuir significado está, em larga medida, dependente do contexto onde é produzida. Parte do presente para o passado e regressa ao presente com experiências para revelar o futuro como referência de acção. Na sua orientação temporal, a consciência histórica liga o passado ao presente de forma a conferir à realidade presente uma perspectiva futura. Esta referência ao futuro está implícita na interpretação histórica do presente porque tais interpretações devem permitir-nos agir, ou seja, devem facilitar a direcção das nossas intenções numa matriz temporal, uma concepção do curso do tempo fluindo pelas vicissitudes da vida quotidiana, guiando o curso da acção. 
A aprendizagem é, para Rüsen (2004), uma qualidade específica dos procedimentos mentais da consciência histórica. A aprendizagem histórica envolve mais do que a simples aquisição de conhecimentos do passado e o aumento desse conhecimento. Vista como um processo em que se adquirem progressivamente competências, emerge como um "processo de mudança das formas estruturais através das quais utilizamos e lidamos com a experiência e o conhecimento da realidade passada, progredindo de formas tradicionais de pensamento para as genéticas" (p. 81). Dependendo da medida em que o conteúdo da consciência histórica seja reconhecido como produto da actividade mental, a aprendizagem de História modifica, perdendo o carácter receptivo inicial e assumindo qualidades produtivas.

Assim, a construção de uma consciência histórica avançada, que permita uma análise crítica e reflexiva do mundo actual, necessita que o conhecimento histórico seja suportado quer pelos "conteúdos" que constituem a substância da História, quer pelo domínio progressivo de conceitos ligados à natureza desse conhecimento (LEE, 2008), tais como as ideias de mudança e de evidência histórica (ASHBY, 2003). Assim, por exemplo, os historiadores fazem inferências sobre fontes, no sentido de saber como foram feitas ou usadas e o que podem ter significado para as pessoas que as produziram e utilizaram (COOPER, 2004), mas alguns elementos chave do pensamento histórico, como as noções de temporalidade, podem ser desenvolvidos de formas mais sofisticadas nos alunos. Estes já conhecem informações acerca do passado mesmo antes de iniciarem a sua educação formal, conhecimentos esses que configuram fortemente a sua identidade e, por isso, devem ser tidos em conta nas experiências educativas que lhes são dirigidas.

Também os sentimentos de pertença e identidade social se constroem no decurso das diversas vivências quotidianas, concorrendo para tal o meio familiar e cultural, os média, a escola... Mas é sobretudo na escola que a identidade social é "aprofundada e (re)orientada através da apropriação que cada um faz da aprendizagem sistemática da História" (BARCA, 2007, p. 116), não devendo, por isso, confundir-se com 'identidade coletiva' (SEIXAS, 2004), mas antes corresponder a identidades múltiplas e em construção progressiva tal como exige a complexidade das sociedades do presente.

O estudo europeu "Youth and History" (ANGVIK e BORRIES, 1997), que procurou investigar os mecanismos individuais e sociais de interiorização do passado histórico pelos jovens, ou seja, de uma "consciência histórica", revelou que os jovens portugueses foram os que mais se manifestaram a favor dos museus e lugares históricos como fontes privilegiadas para a aprendizagem da História. Todavia, as aprendizagens mais recorrentes nas suas aulas 
concentraram-se em duas dimensões: a factual - "procuramos conhecer os principais factos da História" - e a regionalista/patrimonial - "aprendemos a valorizar a preservação das ruínas históricas e das construções antigas" e "aprendemos a reconhecer as tradições, características, valores e tarefas da nação e da sociedade" (PAIS, 1999, p. 54). A relação com o património é, por isso, fundamental para a construção de identidades pelos jovens. Nesse sentido, é essencial que os professores tomem consciência da importância do uso da evidência de acordo com critérios metodológicos da História e tenham preparação no ensino a partir de objectos e sítios históricos, dado que isso essa competência ou a sua falta pode auxiliar ou restringe o desenvolvimento da consciência patrimonial (e histórica) dos estudantes e a compreensão das interpretações históricas (CHAPMAN, 2017).

\section{Método do estudo}

O estudo empírico, de natureza qualitativa, aqui apresentado correspondeu a uma experiência piloto na qual, entre outros objectivos, se procurou conhecer de que forma os professores usam fontes patrimoniais em atividades de ensino de História e que tipos de consciência revelam em termos de relação identitária com o património. Vinte e seis professores dos $2 .^{\circ}$ e $3 .^{\circ}$ ciclos do ensino básico e do ensino secundário (ensino fundamental e médio no Brasil), licenciados em História, a lecionar em escolas do norte de Portugal e a realizar formação contínua, responderam a um questionário com três questões de resposta aberta, relativas a uma atividade educativa com fontes patrimoniais que deveriam propor como projeto de formação ${ }^{2}$.

Q.1 - Que relação com o currículo da disciplina destacaria na proposta de atividade?

Q.2 - O que pensa que os alunos poderiam aprender com a atividade proposta?

Q.3 - De que forma poderá uma atividade deste tipo ajudar os alunos a inferirem, a partir das fontes patrimoniais observadas, sobre o contexto (social, cultural, político, económico) abordado?

A primeira questão destinava-se a conhecer a articulação com os documentos institucionais. Com a segunda questão, pretendia-se conhecer as ideias dos professores sobre o que esperam que os alunos aprendam a partir de uma abordagem de educação patrimonial.

\footnotetext{
2 As questões foram colocadas em contexto de formação contínua a 12 professores a lecionar História e Geografia de Portugal a alunos do $2 .^{\circ}$ ciclo do ensino básico; 10 professores a lecionar História a alunos do $3 .^{\circ}$ ciclo do ensino básico e 4 professores a lecionar História e/ou História da Cultura e das Artes a alunos do ensino secundário.
} 
A terceira questão, mais específica, sobre a forma como explicam o modo como os alunos poderiam inferir sobre o contexto a partir da abordagem utilizada, e sendo uma questão mais direta (usando os termos inferir e contexto), poderia ajudar a compreender as estratégias usadas pelos professores, para implementar essas atividades de ensino e aprendizagem.

\section{Análise de dados}

A análise de dados baseou-se nas interpretações dos professores acerca do uso de fontes patrimoniais para apoiar as experiências de aprendizagem dos alunos, e inspirou-se em estudos considerados relevantes nas áreas de investigação em Educação Histórica e em Consciência Histórica (ASHBY, LEE e SHEMILT, 2005; COOPER, 2004; LEE, 2005; NAKOU, 2001, 2003; RÜSEN, 2004; WERTSCH, 2000).

Usaram-se procedimentos de codificação que caracterizam a Grounded Theory (STRAUSS e CORBIN, 1998), teoria que se constrói progressivamente através da recolha sistemática de dados e da sua análise constante.

Esta análise, embora limitada quanto ao âmbito de aplicação, revelou diversos perfis conceptuais relativamente a dois construtos: (a) Uso da evidência e (b) Finalidades de ensino e divulgação do património, nomeadamente no que respeita à forma como os professores propõem desenvolver a compreensão histórica dos alunos, ao tipo de aprendizagem a realizar por estes e à consciência patrimonial, i.e., à relação identitária com o património (Figura 1).

Figura 1. Esquema conceptual da análise das respostas dos professores

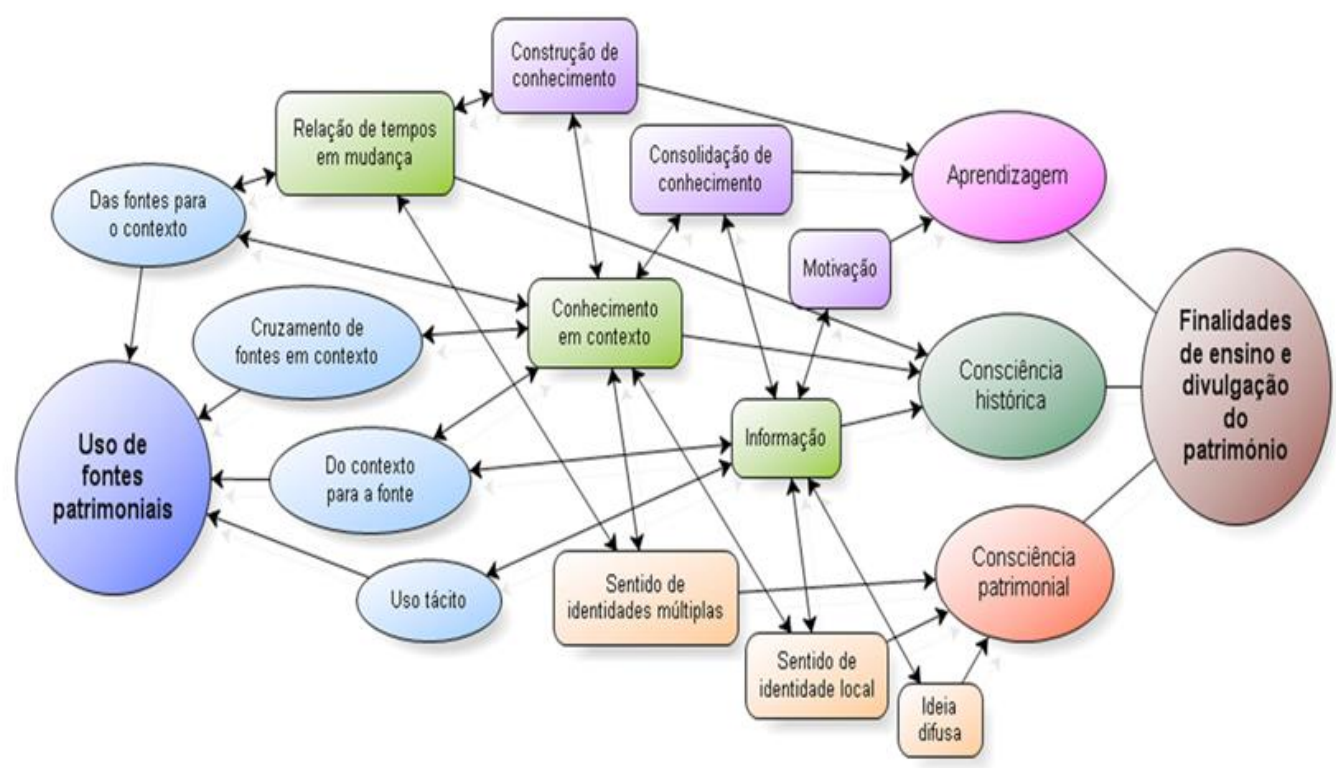

Fonte: Produção da autora. 
Apresentam-se, de seguida, alguns exemplos das perspectivas de professores sobre o uso de fontes patrimoniais no ensino e aprendizagem de História, as quais se integram nas dimensões de análise referidas.

\section{Uso da evidência}

Os professores são mediadores entre os vestígios do passado e os seus alunos. Por isso, devem refletir sobre o seu papel nesta relação, tendo em conta a compreensão das fontes como evidência histórica pelos alunos.

Correspondendo a um perfil de menor elaboração - Informação - as respostas de alguns professores referem o contributo das atividades relacionadas com património para a aprendizagem dos alunos, mas sem clarificarem como poderiam usar as fontes patrimoniais. Referem informação retirada dos documentos oficiais (fragmentos). Para esses professores, uma atividade baseada na observação direta do património seria "uma forma de ensinar História a partir das suas manifestações, em que se parte do concreto, do conhecido para o desconhecido" (Célia, professora do ensino secundário, Q.3). Outros consideram que "tudo depende não só da fonte que se escolhe, ser mais ou menos rica, como do estudo e desenvolvimento que se dê ao que foi selecionado (Márcia, professora do 2..$^{\circ}$ ciclo do ensino básico, Q.2).

Já no perfil Do contexto para a fonte, as respostas de alguns professores sugerem aa realização de uma visita de estudo focando monumentos e usando as fontes patrimoniais como ilustração da informação já fornecida, e não como pesquisa conceptual (ASHBY, 2003): “através de uma visita de estudo a um monumento localizado na região, estes [alunos] conseguem reconhecer e identificar, no local, as principais características dos estilos românico e gótico" (Artur, professor do 3. ${ }^{\circ}$ ciclo do ensino básico, Q.2).

Abordando o passado tendo em consideração as fontes como coleção de informação, não como fragmentos - cruzamento de fontes em contexto - alguns professores consideram que a maior vantagem da observação dos vestígios do passado é a sua proximidade:

Muitas vezes os nossos alunos vêm a História como algo distante, algo que não toca o seu universo imediato; afinal, a História dos manuais está mesmo 'ao virar da rua', naquele local por onde tantas vezes passaram e que pouco valorizaram. (Marisa, professora do 3. . ciclo do ensino básico, Q.2).

Tais vestígios materializam o passado (LOWENTHAL, 1999) proporcionando aos alunos a possibilidade de lidarem com as fontes como evidência (ASHBY, 2003): “a 
observação das fontes patrimoniais, nomeadamente os prédios de época, é uma realidade muito diferente da que observam no seu dia-a-dia e do seu próprio espaço de habitação, em muitos casos ainda semirrural.” (Flor, professora do 2. ciclo do ensino básico, Q.3).

Apenas um pequeno grupo de professores referiu o processo de construção de conhecimento a partir das fontes patrimoniais - das fontes para os contextos - reconhecendo o facto de elas proporcionarem a interpretação de modos de vida diferentes dos do presente (NAKOU, 2001) e a compreensão de distintos contextos:

As fontes utilizadas permitem aos alunos [...] inferirem que [a cidade] ocupava um lugar de destaque no século XIX, em termos industriais, lugar que viria a manter em termos, por exemplo, de indústria de fiação, tecelagem e cutelaria, até há bem pouco tempo. (Ana, professora do $2 .^{\circ}$ ciclo do ensino básico, Q.3).

Usando uma diversidade de fontes - textos, objectos, edifícios - as atividades educativas permitem uma abordagem multisensorial, provocando um diálogo histórico com significado entre os sujeitos e o passado:

Os alunos ao observarem com atenção a localização do mosteiro e espaço envolvente, a grandeza deste monumento, as partes que o constituíam e os pormenores da sua construção podem depreender [...] que o clero era um grupo social com prestígio e grande poder económico. Ao analisarem as partes constituintes deste monumento religioso podem inferir sobre a vida quotidiana nos mosteiros. (Clara, professora do $3 .^{\circ}$ ciclo do ensino básico, Q.3).

\section{Finalidades de ensino e divulgação do património}

Sendo mediadores entre os vestígios do passado e os seus alunos, os professores devem reflectir também sobre a forma como podem ajudar a desenvolver o pensamento histórico dos alunos, procurando ter consciência desse processo e da relação identitária dos alunos com o património.

Em relação ao processo de aprendizagem de História pelos alunos, os professores revelam concepções diversas quanto aos objetivos e procedimentos de contacto direto com fontes patrimoniais e sua exploração. Algumas respostas mostram interesse em que os alunos vejam o passado como algo que esteja próximo da sua experiência quotidiana - motivação mostrando uma tendência para o "presentismo" (LEE, 2005), ou seja, para verem o passado como algo útil e/ou idêntico ao presente: "compreender o passado da sua comunidade e dos seus "antepassados", aliado a um sentido de "aventura" e de descoberta, característico do adolescente.” (Goreti, professora do ensino secundário, Q.3). 
Alguns professores admitem implicitamente a consolidação de conhecimento como o principal objectivo do contacto com as fontes patrimoniais; outros fazem-no explicitamente: sugerindo que essas "cultural tools" (WERTSCH, 2000), utilizadas para ajudar os alunos a darem sentido ao passado, podem auxiliar a compreensão histórica dos alunos: "guardassem na sua memória a riqueza que um edifício deste tipo contém enquanto testemunho de manifestações artísticas e religiosas de outras épocas." (Laura, professora do 3. ciclo do ensino básico, Q.2).

Noutras respostas parece claro que o papel do professor deverá ser o de proporcionar aos alunos a orientação, quando necessária, no seu diálogo com as fontes patrimoniais, interpretadas como evidência histórica - construção de conhecimento. Desta forma o pensamento dos alunos pode tornar-se mais sofisticado:

Propor a discussão de situações do quotidiano e de fontes locais, levando os alunos a formarem opiniões fundamentadas e argumentarem de acordo com as fontes que lhes são sugeridas. Eles sentir-se-ão, certamente, "fazedores" de história e valorizarão o seu património. (Selma, professora do $3 .^{\circ}$ ciclo do ensino básico, Q.3).

Em termos de consciência patrimonial, nomeadamente no que respeita à consciência acerca da relação identitária dos alunos com o património, os professores revelam concepções diversas quanto à atitude dos alunos face os vestígios do passado.

Alguns professores realçam o facto de as actividades com fontes patrimoniais proporcionarem a sensibilização para a preservação do património local - sentido de identidade local - mas ainda relacionadas diretamente com a consolidação de conhecimentos:

As actividades propostas têm como principais objectivos sensibilizar os alunos para a importância da divulgação e preservação do Património Local, aplicar e consolidar os conhecimentos adquiridos nas aulas lecionadas, com o intuito destes ficarem a conhecer um monumento de grande valor patrimonial, pertencente à sua região (Sofia, professora do ensino secundário, Q.2).

Salientando o respeito pelo património, pelas marcas do passado que pode ser evocado para uso no presente, outros professores parecem revelar uma consciência de tipo “tradicional” (RÜSEN, 2004), que implica que o sujeito se considere condicionado pelos seus ancestrais e o comprometimento com uma determinada identidade colectiva:

Ao conhecer o seu património e a história da sua comunidade os alunos "apropriam-se" dele, sentem-se parte dele e se não se apaixonarem por ele, 
de certeza que o passam a respeitar e defender como parte integrante da sua identidade. (Célia, professora do ensino secundário, Q.3).

Outros professores pareceram considerar que o património local materializa a identidade da comunidade, mediando uma mensagem para as jovens gerações como depositário de casos "exemplares" (RÜSEN, 2004) relevantes para a resolução dos seus problemas do presente:

É de extrema importância que nas escolas se comece a utilizar o património local como recurso educativo, para que a população crie uma relação mais forte com a sua herança cultural, compreender melhor o modo de vida dos nossos antepassados, os problemas que enfrentaram e como os solucionaram. Ao apoderarem-se destes conhecimentos a população poderá projectar melhores soluções para os problemas que enfrenta, e não repetir os mesmos erros do passado (Laura, professora do $3 .^{\circ}$ ciclo do ensino básico, Q.2).

A um nível mais elaborado, para um pequeno grupo de professores, é possível ensinar a partir da observação do local para o quadro nacional. Através da análise das fontes do património local, os alunos experienciam oportunidades de exploração de questões acerca da identidade - sentido de identidades múltiplas - permitindo que as narrativas dominantes ou alternativas (enraizadas em mitos ou noções de identidade) possam ser verificadas, validadas ou refutadas, promovendo uma consciência mais sofisticada do passado:

Estimular nos alunos o raciocínio e o espírito crítico, numa perspectiva de valorizarem os aspectos positivos na abordagem de conteúdos, sem escamotear os negativos, valorizando o que une as diferentes épocas e culturas. Propor a discussão de situações do quotidiano e de fontes locais, levando os alunos a formarem opiniões fundamentadas. Sentir-se-ão, certamente, "fazedores" de história e valorizarão o seu património. (Selma, professora do 3..$^{\circ}$ ciclo do ensino básico, Q3).

Em termos gerais, as referências dos professores relativamente ao uso de fontes patrimoniais no ensino de História parecem situar-se quer no seu ambiente cultural e educacional quer no contexto da investigação. A formulação das questões - de carácter mais geral na primeira, ou mais directa na segunda, usando os termos 'inferir' e 'contextualizar') podem ter influenciado uma explanação menos ou mais clara pelos professores (Figura 2). 
Figura 2. Ideias dos professores nas respostas ao questionário.

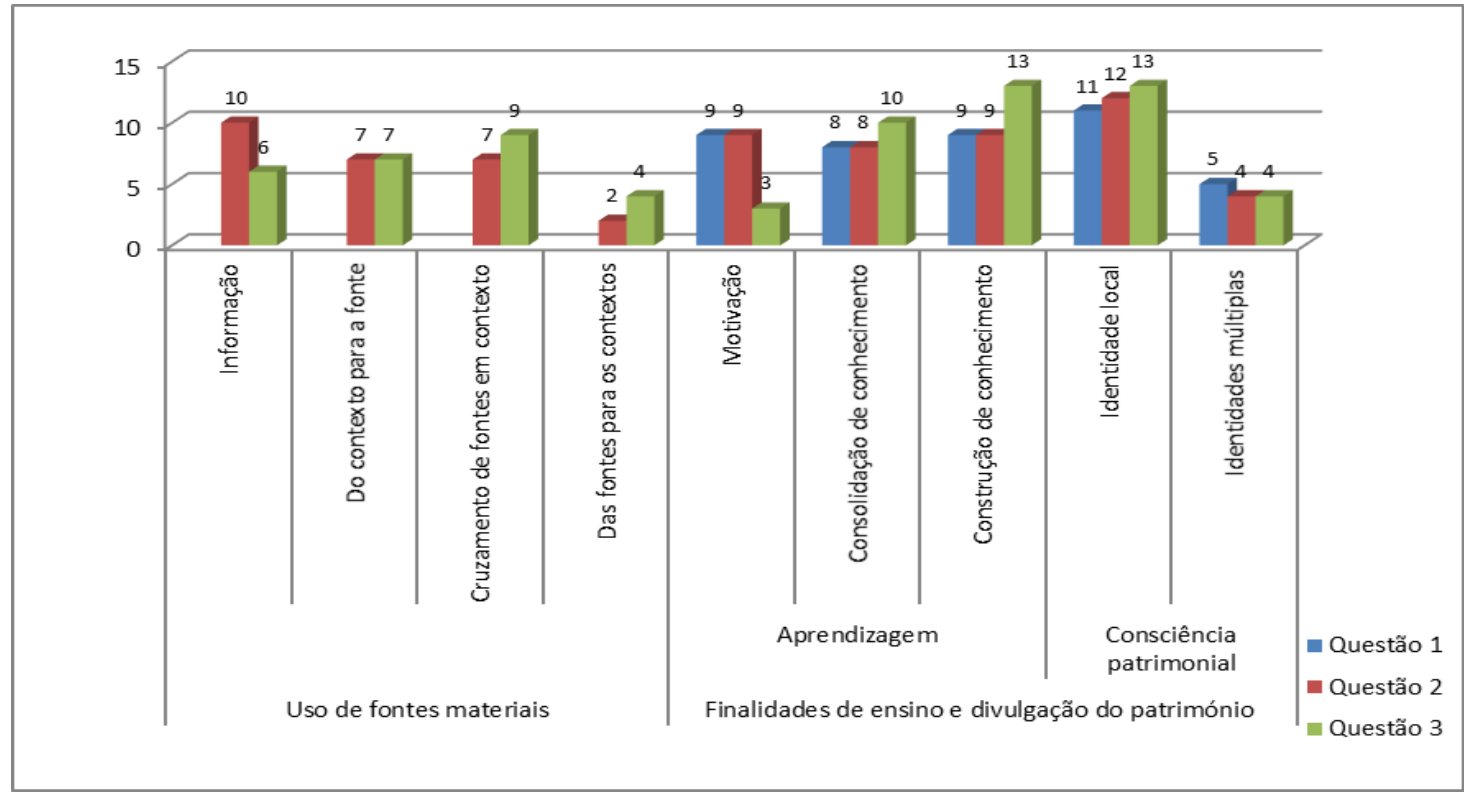

Fonte: Produção da autora

Os professores oscilaram entre uma referência vaga aos contributos do uso de fontes patrimoniais para a aprendizagem dos alunos, um foco na ideia de fonte como ilustração, e uma relação entre fontes e contexto, considerando que aquelas materializam o passado. Apenas um pequeno grupo de professores fez referência a um processo de construção do conhecimento com base na evidência histórica, proporcionando uma aprendizagem com significado. Quanto às finalidades de ensino e divulgação do património, nomeadamente acerca da forma como propõem desenvolver a compreensão histórica dos alunos, alguns professores salientaram o carácter estimulante ou motivador da actividade ao trazer o passado para a experiência quotidiana dos alunos; outros destacaram a consolidação de conhecimento como o principal objectivo do contacto directo com fontes patrimoniais; e outros, ainda, realçaram a construção do conhecimento pelos alunos, orientada pelos professores. Por sua vez, no que respeita à consciência patrimonial, ou seja, à relação identitária com o património, os dados revelaram similaridades com alguns dos tipos de consciência histórica propostos por Rüsen (2001, 2004): os professores pareceram orientar-se sobretudo por posições de tipo 'tradicional' e 'exemplar' em relação ao passado, uma vez que a sua relação com o património revela uma ideia implícita de compromisso com uma certa identidade colectiva ou um sentido de identidade em relação a uma comunidade, materializada pelo património local que veicula u para as gerações mais novas; apenas alguns professores sugeriram uma 
‘temporalização' e construção de identidades múltiplas, características que se poderiam identificar com uma consciência de tipo "genético".

\section{Considerações Finais}

Salientam-se algumas implicações deste estudo, nomeadamente no âmbito da Educação Histórica e da sua relação com o património, e sobre as quais se está a aprofundar a reflexão e análise em projecto de doutoramento:

Sendo o património uma construção social, é essencial a sua investigação e interpretação. É, por isso, fundamental a realização de estudos sistemáticos sobre experiências educativas com alunos e professores, envolvendo a exploração de fontes patrimoniais relacionadas com a história local/regional (PINTO e ZARBATO, 2017), pois a progressão no pensamento histórico envolve, acima de tudo, aprendizagens significativas, em contexto. Poderão ainda contribuir para a construção da componente histórica das identidades dos alunos, numa época em que a existência de múltiplas e complexas identidades torna inapropriada a ideia de 'identidade colectiva'.

Uma reflexão sistemática acerca de propostas de actividades de contacto directo com fontes patrimoniais poderá levar os professores a tomarem consciência da importância do uso do património como ferramenta cultural passando a integrar as experiências de aprendizagem dos alunos, e simultaneamente, levar a que a educação patrimonial seja progressivamente reconhecida no currículo nacional.

Os resultados deste e de outros estudos (PINTO e SQUINELO, 2017) acerca das concepções de professores sobre o uso de fontes patrimoniais no ensino e aprendizagem de História, salienta o interesse da sua utilização nas experiências educativas, defendendo que os professores podem desempenhar um papel fundamental para que os alunos dêem sentido ao património como evidência histórica, e não apenas como simples ilustração. O contacto direto com fontes patrimoniais, se os edifícios, individualmente ou integrados em espaços urbanos, os sítios históricos e os objectos dos museus forem interpretados em termos de evidência histórica, pode contribuir para um ensino e uma aprendizagem de História mais consistentes 


\section{Referências}

ANGVIK, M.; BORRIES B. (Eds.). Youth and History: a comparative European survey on historical consciousness and political attitudes among adolescents. Hamburg: KörberStiftung, 1997.

ASHBY, R. O conceito de evidência histórica: exigências curriculares e concepções dos alunos. In I. BARCA (Org.), Educação Histórica e Museus. Actas das Segundas Jornadas Internacionais de Educação Histórica. Braga: CIEd, Universidade do Minho, 2003, p. 37-57.

Desenvolvendo um conceito de evidência. Educar em revista, número especial, 2006, p. 151-170.

ASHBY, R.; LEE, P.; SHEMILT, D. Putting principles into practice: teaching and planning. In M. S. DONOVAN; J. D. BRANSFORD (Eds.), How students learn: History in the classroom. Washington DC: The National Academies Press, 2005, p. 79-178.

BARCA, I. Marcos de consciência histórica de jovens portugueses. Currículo sem Fronteiras, 7(1), 2007, 2 p. 115-126. 0 Retirado de http://www.curriculosemfronteiras.org/vol7iss1articles/barca.htm. [07/10/2019].

COOPER, H. The teaching of History: implementing the national curriculum. London: David Fulton, 1992.

Why time? Why place? Why play? In H. Cooper (Ed.), Exploring time and place through play. London: David Fulton, 2004, p. 5-23.

FOSNOT, C. Construtivismo: uma teoria psicológica da aprendizagem. In C. FOSNOT (Ed.), Construtivismo e Educação: teoria, perspectivas e prática. Lisboa: Instituto Piaget, 1999, p. 23-58.

HOOPER-GREENHILL, E. The educational role of the museum. London: Routledge, 1999.

LEE, P. 'Walking backwards into Tomorrow': historical consciousness and understanding History, 2002. Retirado de http://www.cshc.ubc.ca [07/12/2018].

Nós fabricamos carros e eles tinham que andar a pé: compreensão da vida no passado. In I. BARCA (Org.), Educação Histórica e Museus. Actas das Segundas Jornadas Internacionais de Educação Histórica. Braga: CIEd, Universidade do Minho, 2003, p. 19-36.

LEE, P. Putting principles into practice: understanding History. In M. S. DONOVAN; J. D. BRANSFORD (Eds.), How students learn: History in the classroom. Washington, DC: The National Academies Press, 2005, p. 31-77.

LEE, P. Educação histórica, consciência histórica e literacia histórica. In I. BARCA (Org.), Estudos de Consciência na Europa, América, Ásia e África. Actas das Sétimas Jornadas Internacionais de Educação Histórica. Braga: CIEd, Universidade do Minho, 2008, p. 11-32.

LEVSTIK, L.; HENDERSON, A.; SCHLARB, J. Digging for clues: an archaeological exploration of historical cognition. In R. ASHBY; P. GORDON; P. LEE (Eds.), 
Understanding history: recent research in History Education. London: Routledge Falmer, 2005, p. 37-53.

LOWENTHAL, D. The past is a foreign country. Cambridge: Cambridge University Press, 1999.

NAKOU, I. Children's historical thinking within a museum environment: an overall picture of a longitudinal study. In A. DICKINSON; P. GORDON; P. LEE (Eds.), Raising standards in History Education. London: Woburn Press, 2001, p. 73-96.

Exploração do pensamento histórico das crianças em ambiente de museu. In I. BARCA (Org.), Educação Histórica e Museus. Actas das Segundas Jornadas Internacionais de Educação Histórica. Braga: CIEd, Universidade do Minho, 2003, p. 59-82.

PAIS, J. M. Consciência histórica e identidade: os jovens portugueses num contexto europeu. Oeiras: Celta Editora, 1999.

PINTO, H. (2009). O triângulo Património-Museu-Escola: que relação com a Educação Histórica? In M. A. Schmidt \& I. Barca (Org.), Aprender História: Perspectivas da Educação Histórica. (pp. 271-302). Ijuí: Ed. Unijuí.

PINTO, H. Educação Histórica e Patrimonial: conceções de alunos e professores sobre o passado em espaços do presente. Tese (doutorado em Ciências da Educação). Universidade do Minho, 2011.

Educação Histórica e Patrimonial: conceções de alunos e professores sobre o passado em espaços do presente. Porto: CITCEM - Centro de Investigação Transdisciplinar «Cultura, Espaço e Memória», 2016.

PINTO, H.; MOLINA, S. La educación patrimonial en los currículos de ciencias sociales en España y Portugal. Educatio Siglo XXI, vol. 33 (1). p. 103-128, 2015. Retirado de: http://revistas.um.es/educatio/article/view/222521/174771 [29/04/2019].

PINTO, H.; SQUINELO, A. P. (2017). O uso do património cultural no ensino de história: perspectivas da formação docente em Portugal e Brasil. Pulso. Revista de Educación, 40, $35-$ 52. Retirado de: http://revistas.cardenalcisneros.es/index.php/PULSO/article/view/253/206. [21/06/2018].

PINTO, H.; ZARBATO, J. (2017), Construyendo un aprendizaje significativo a través del patrimonio local: prácticas de Educación patrimonial en Portugal y Brasil. Estudios Pedagógicos, 43(4), 203-227. DOI: http://dx.doi.org/10.4067/S0718-07052017000400011. [21/06/2018].

RAMOS, F. R. A danação do objeto: o museu no ensino da história. Chapecó: Argos, 2004.

RÜSEN, J. Razão histórica. Teoria da História: os fundamentos da ciência histórica. Brasília: Editora UnB, 2001.

Historical Consciousness: Narrative Structure, Moral Function, and Ontogenetic Development. In P. Seixas (Ed.). Theorizing Historical Consciousness. Toronto: University of Toronto Press, 2004, p. 63-85. 
SANTACANA, J.; LLONCH, N. Manual de didáctica del objeto. Gijón: Ed. Trea, 2012.

SANTACANA, J.; MARTINEZ, T. Patrimonio, identidad y educación: una reflexión teórica desde la historia. Educatio Siglo XXI. 31 (1), p. 47-60, 2013.

SCHMIDT, M. A.; GARCIA, T. B. O trabalho com objetos e as possibilidades de superação do sequestro da cognição histórica: estudo de caso com crianças nas séries iniciais. In M. A. SCHMIDT; T. B. GARCIA (Org.), Perspectivas de Investigação em Educação Histórica. Curitiba: UFPR, 2007, vol. I, p. 52-57.

SEIXAS, P. (Ed.). Theorizing Historical Consciousness. Toronto: University of Toronto Press, 2004.

SHEMILT, D. Adolescent ideas about evidence and methodology in history. In C. PORTAL (Ed.), The history curriculum for teachers. London: The Falmer Press, 1987, p. 39-61.

Strauss, A. \& Corbin, J. (1998). Basics of qualitative research: techniques and procedures for developing Grounded Theory. Thousand Oaks: Sage.

WERTSCH, J. Is it possible to teach beliefs, as well as knowledge about history? In P. STEARNS; P. SEIXAS; S. WINEBURG (Eds.), Knowing, teaching, and learning history: national and international perspectives. New York: New York University Press, 2000, p. 3850 .

Recebido em: 11/10/2019

Aprovado em: 08/04/2020 